\title{
CASTIGO PENAL, INJUSTICIA SOCIAL Y AUTORIDAD MORAL
}

\author{
EDUARDO RIVERA LÓPEZ \\ Universidad Torcuato Di Tella
}

\section{Resumen}

La pregunta que exploro en este trabajo es si la injusticia social puede socavar la autoridad moral de la sociedad (y los tribunales) para castigar al que delinque. La respuesta a esta pregunta depende esencialmente de cuál sea la teoría justificatoria del castigo penal de la que se parte. Analizo diversas teorías de la pena, entre ellas la teoría consensual de Carlos Nino. Mi objetivo es explorar de qué modo las diferentes teorías de la pena enfrentan el desafío que plantea la pregunta y extraer algunas conclusiones tentativas de ese recorrido.

PALABRAS CLAVE: Autoridad moral; Castigo penal; Teoría de la pena; Carlos Nino; Teoría disuasoria; Retribucionismo.

\begin{abstract}
The question I address in this paper is whether social injustice can undermine the moral authority of society (and judges) to punish criminals. The answer to this question crucially depends on the underlying justificatory theory of punishment. I consider several theories, among them the consensual theory proposed by Carlos Nino. My aim is to explore how different theories of punishment address the challenge and to draw some tentative conclusions.
\end{abstract}

KEY WORDS: Moral Authority; Criminal Punishment; Theory of Punishment; Carlos Nino; Deterrent Theory; Retributionism.

\section{Introducción}

La obra de Carlos Nino es extensa, multifacética y original. Dentro de los muchos temas que abarca, la justificación del castigo penal, la justicia distributiva y la teoría de la democracia son tres de los más relevantes. En todos ellos Nino nos ha legado teorías originales y aportes concretos: su teoría consensual de la pena, su ética de los derechos humanos, y su teoría de la democracia deliberativa. La pregunta que me planteo en este trabajo se refiere a la relación entre la justificación del castigo penal y la injusticia social. Nino menciona el problema al menos en dos contextos: al reflexionar sobre la relación entre derecho penal y 
democracia, ${ }^{1}$ y al discutir las tesis de Eugenio Zaffaroni sobre la legitimidad de la pena. ${ }^{2}$ En su discusión con Zaffaroni, la preocupación fundamental es si la injusticia social puede socavar el consentimiento genuino del que delinque (cuestión que, como veremos, es crucial para su teoría del castigo). La pregunta que voy a explorar en este trabajo es, de algún modo, su contracara: si la injusticia social puede socavar la autoridad moral de la sociedad (y los tribunales) para castigar al que delinque. ${ }^{3}$ Dado que la respuesta a esta pregunta depende esencialmente de cuál sea la teoría justificatoria del castigo penal de la que se parte, me referiré a la teoría consensual de la pena de Nino, aunque mi perspectiva será más amplia. Mi objetivo es explorar de qué modo las diferentes teorías de la pena enfrentan el desafío que plantea la pregunta y extraer algunas conclusiones tentativas de ese recorrido.

El plan del trabajo es el siguiente. En primer lugar, realizo algunas aclaraciones preliminares que permitirán precisar la pregunta (sección II). Luego, explico la tesis que niega la autoridad moral para castigar (que llamo "tesis de la incapacidad") (sección III). En la sección IV, evalúo la tesis de la incapacidad desde el punto de vista de teorías que conciben al castigo penal como una expresión o comunicación de un reproche moral. En las secciones siguientes, realizo la misma evaluación desde la perspectiva de la teoría retribucionista (sección V), de la teoría consensual de Nino (sección VI) y de la teoría prevencionista (sección VII). En la última sección (VIII), extraigo el resultado del recorrido y realizo algunas reflexiones adicionales que limitan el alcance de la tesis de la incapacidad.

\section{Aclaraciones preliminares}

Comienzo con algunas aclaraciones preliminares. En primer lugar, asumo que, cuando nos preguntamos por la legitimidad del castigo penal (sea en general o en un determinado contexto), nos preguntamos por la legitimidad moral de esta práctica. Preguntamos por una permisión moral y, quizá, por una obligación moral. La pregunta es, entonces, centralmente normativa y pertenece, por lo tanto, a la teoría moral (o a la ética) en un sentido amplio, y no al derecho.

${ }^{1}$ Entre otros lugares, Nino se refiere a esta relación en Nino (1989/2007). Roberto Gargarella se refiere a ella extensamente en su contribución a este homenaje.

2 Véase Nino (1991/2007, pp. 138-139) y (1992/2007, pp. 152-153).

${ }^{3}$ La pregunta ha sido planteada por diversos autores de diversos modos. Véase Gargarella (2011), Duff (2004, pp. 257-259), Murphy (1973, p. 221), Tadros (2009). 
En segundo lugar, la pregunta que me planteo, además de ser una pregunta moral, es una pregunta de teoría moral no ideal. ${ }^{4}$ Debemos establecer cuestiones de legitimidad moral en contextos en los que se supone que existe un incumplimiento sustancial de principios o deberes morales, tanto por parte de individuos como por parte de autoridades e instituciones. Esto hace que la pregunta sea compleja, en el sentido de que sugiere (aunque no implica) que, si la injusticia social no existiera, entonces la pena sí sería legítima. El problema se produciría en el pasaje de un escenario (ideal de justicia) a otro (real de injusticia). Sin embargo, la injusticia social existente podría no ser la (única) razón de la ilegitimidad del castigo, dado que este podría estar injustificado incluso en condiciones de justicia social. Por ello, es necesario deslindar diferentes razones que pueden ofrecerse en contra del castigo, de modo de identificar aquellas que específicamente se vinculan con la injusticia y la exclusión.

En tercer lugar, voy a establecer algunos supuestos respecto del concepto de castigo penal. Tomo como marco la definición tradicional de castigo como la aplicación intencional de "dolor u otra consecuencia normalmente considerada displacentera" por una ofensa en contra de las reglas jurídicas, impuesta por una autoridad jurídica. ${ }^{5} \mathrm{~A}$ los efectos de este trabajo, sin embargo, la pregunta de si es moralmente justificable el castigo penal en contextos realistas de (alegada) injusticia social significa fundamentalmente si es justificable la institución de la cárcel, es decir, la privación de la libertad durante un período no trivial de tiempo. Excluyo de mi tratamiento otras clases de castigo, algunas de las cuales se utilizan frecuentemente (como multas, trabajos comunitarios), otras de las cuales resultan inaceptables por razones (deontológicas) independientes (como trabajos forzados, pena de muerte, azotes, etc.). Supongo, además, que la imposición coercitiva del encierro carcelario se realiza siguiendo las pautas establecidas por las instituciones del derecho vigente: imputación, procesamiento (con probable prisión preventiva) y eventual condena, de acuerdo con las reglas del derecho procesal penal. Esto incluye, de modo relevante, ciertas garantías procesales. Por supuesto, en la medida que tratamos el problema en condiciones realistas, este tratamiento debe incluir el funcionamiento defectuoso de estas instituciones. ${ }^{6}$

${ }^{4}$ La distinción entre teoría ideal y no ideal se encuentra en Rawls (1971, p. 8). Para un panorama sobre el tema de la ética no ideal, véase Rivera López (2013).

5 Tomo la definición de Hart (1968, pp. 4-5).

${ }^{6}$ La restricción de referirme a la cárcel como tipo fundamental de castigo no es esencial para mi análisis. La establezco por razones de simplicidad, y porque creo que 
Por último, el alcance de la pregunta abarca estrictamente la aplicación de la cárcel como castigo mediante las instituciones del derecho penal. Aun cuando la conclusión a la que arribáramos fuera que esta aplicación es ilegítima en muchos casos, esto no afecta a un número importante de tareas y prácticas ligadas al derecho penal, como la prevención del delito mediante la acción policial, la utilización de medidas coercitivas tendientes a rehabilitar o resocializar, la incapacitación de personas especialmente peligrosas, entre otras. Estas prácticas, en todo caso, merecen un análisis independiente.

\section{La tesis de la incapacidad}

Es un lugar común que nuestras sociedades actuales son, en una medida importante, injustas. ¿Por qué la mayor o menor injusticia social podría incidir en el hecho de hacer legítimo o ilegítimo el castigo de personas que son culpables de cometer delitos? De los diversos argumentos que han sido propuestos, me interesa identificar y discutir, en particular, el que conecta la injusticia social con la incapacidad moral (o falta de autoridad moral) del estado para castigar. Esta visión es la que defiende lo que he denominado "tesis de la incapacidad". Paso ahora a explicar esta tesis con más detalle.

La tesis de la incapacidad se basa en la existencia de una situación de injusticia o violación de derechos de la población relevante. Esta injusticia consistiría en al menos los tres siguientes hechos: ${ }^{7}$

1. En primer lugar, se trata de personas que pertenecen a los estratos socioeconómicos más bajos, con chances casi nulas de ascenso o progreso social. Sus historias vitales se caracterizan por carencias profundas en relación con bienes básicos, como la educación, la salud, la alimentación, así como un medio familiar

efectivamente, dentro de un orden jurídico como el nuestro, es el tipo de pena más relevante y controvertido. Pero es posible que la misma clase de argumentos que voy a evaluar a continuación puedan ser realizados respecto de otros castigos.

${ }^{7}$ Para una descripción similar de las condiciones de exclusión social de la población carcelaria, véase Green (2011, pp. 354-356). También hace referencia a estos mismos puntos Nino (1991/2007, p. 139). Los tres puntos señalados no pretenden ser exhaustivos. Intentan abarcar al menos tres aspectos en los que tiene sentido hablar de exclusión social: la pobreza y desigualdad socioeconómica, el maltrato por parte del propio sistema penal y la falta de oportunidades de participación ciudadana. Se puede discutir cuál es más importante. De cualquier modo, esta discusión no es muy relevante, dado que los tres están presentes en la mayoría de los casos. 
y social adecuado (incluyendo condiciones materiales como la vivienda digna). ${ }^{8}$

2. Por otro lado, los sectores que mayormente pueblan las cárceles son sistemáticamente maltratados por el propio sistema penal: falta de acceso a buenos abogados (debiendo recurrir a defensores de oficio, normalmente sobrepasados de trabajo), discriminación por clase social o pertenencia étnica, carencia de recursos para sostener a las familias durante el encarcelamiento, etc.

3. Por último, la población carcelaria pertenece a un sector social que carece de cualquier recurso para hacer oír su voz públicamente (acceso a medios de comunicación, contactos políticos, acceso a ser oídos por los órganos de gobierno).

Llamaré, convencionalmente, "excluidos sociales" a aquellos que pertenecen al sector social que satisface los puntos mencionados. Tal como indiqué anteriormente, este es el sector que en muchas sociedades contemporáneas es el objeto predominante de persecución penal.

La tesis de la incapacidad presupone que la exclusión social es el producto de una situación en la cual los excluidos sociales son, en alguna medida, víctimas de la injusticia social imperante. Este presupuesto es, ciertamente, discutible, sobre todo si se pretende desprender de él una responsabilidad o culpabilidad de la sociedad (o de sus autoridades jurídicas), o la existencia de una violación de derechos hacia los excluidos sociales. No puedo discutir este supuesto aquí. Sin embargo, me parece al menos plausible asumir que, en una sociedad de ingresos medios, la existencia de personas que carecen de los medios mínimos para satisfacer sus necesidades básicas, así como de la posibilidad de ejercer adecuadamente sus derechos procesales o de participación, implica alguna clase de injusticia que hace a los ciudadanos más aventajados y a la dirigencia política responsables en alguna medida.

${ }^{8}$ Sin intentar comprobar este hecho empíricamente, consideremos, por mencionar solo un bien social fundamental, el caso de la educación. En el "Sistema Nacional de Estadísticas sobre la Ejecución de la Pena", del Ministerio de Justicia y Derechos Humanos de la Argentina, consta que el 7\% de los presos en el país carece de toda educación formal (serían probablemente analfabetos), el $27 \%$ no ha terminado educación primaria y el $40 \%$ sí la ha terminado pero no ha continuado su educación. A esto se agrega un $15 \%$ con estudios secundarios incompletos. Esto significa que aproximadamente un $90 \%$ de la población carcelaria no ha accedido a la educación que el propio estado considera que todos los habitantes tienen derecho a recibir; en su gran mayoría, ni siquiera cercanamente. 
Los excluidos sociales son, entonces, el universo relevante de aplicación de la tesis de la incapacidad. Esto significa que la incapacidad para castigar solo se referiría a cierta población carcelaria, no necesariamente a toda persona penalmente castigada. En este sentido, la tesis de la incapacidad no es una tesis abolicionista (aunque sea compatible con el abolicionismo, obviamente). Solo cuestiona el castigo de cierta clase de individuos. Como veremos, esta es una restricción muy significativa y no poco problemática.

Es necesario también precisar la razón que motiva a la tesis de la incapacidad y distinguirla de otras diversas razones que se han alegado para objetar la persecución y castigo penal hacia los excluidos sociales (o hacia otros). Una objeción frecuente al castigo carcelario de los excluidos sociales es, simplemente, que muchas de las conductas por las que son perseguidos penalmente no deberían ser delitos. Por ejemplo, una parte importante de la población carcelaria se encuentra vinculada a la comercialización de drogas en menor escala. El argumento aquí podría ser que ese tipo de actividad no debería ser penalizada (suponiendo una posición pro legalización del consumo y comercio de drogas). Otra clase de argumentos que liga la injusticia social y la pobreza con la ilegitimidad del castigo se concentra en la existencia de excusas ligadas a la condición social de exclusión. Aquí la idea sería que estas personas no son responsables. No pueden ser culpabilizadas porque su condición desesperante les quita la libertad relevante para ser imputables, consistente en poseer alguna alternativa razonable a la comisión del delito. ${ }^{9}$ Ninguna de estas objeciones es la contenida en la tesis de la incapacidad. En este sentido, la objeción es consistente con que la conducta del excluido social sea justificadamente un delito penal (una conducta incorrecta) y la persona sea, parcial o totalmente, culpable por haberla realizado. La objeción a la cárcel que me interesa analizar y evaluar es específicamente aquella que dice que, aun siendo el acusado culpable, no tenemos derecho a castigarlo por carecer el tribunal, que de algún modo representa a la sociedad, de suficiente autoridad moral para ello.

Conectado con esto, es importante, por último, señalar que la tesis de la incapacidad no se refiere necesariamente a todos los delitos cometidos por la población relevante, sino solo a aquellos que están, de algún modo, conectados con la naturaleza de la injusticia que se ha ejercido sobre ellos. La conexión entre la injusticia sufrida y el delito

${ }^{9}$ Para un desarrollo detallado de la excusa por razones sociales, véase Delgado (1985). Para la distinción entre este punto y el siguiente, véase Duff (2004, p. 258), Tadros (2009, p. 392). 
cometido debe explicar la incapacidad o pérdida de autoridad moral para castigar de las autoridades jurídicas. Como veremos, no cualquier conexión habilita está pérdida.

Podemos resumir entonces la tesis de la incapacidad del siguiente modo: El castigo penal (entendido como la imposición del encierro carcelario) es moralmente ilegítimo (al menos) cuando (i) se aplica a (los que he denominado) excluidos sociales y (ii) los delitos por los que se aplica el castigo tienen una conexión relevante con el tipo de exclusión que sufren; $y$ todo esto, a pesar de (o incluso en los casos en los) que el individuo castigado es responsable moralmente por el delito cometido. La razón por la cual el castigo penal es ilegítimo es la ausencia de autoridad moral para castigar por parte de las autoridades jurídicas.

La plausibilidad que le otorguemos a la tesis de la incapacidad depende, en buena medida, de cuál sea la justificación moral que creamos que posee el castigo penal (si es que posee alguna). La tesis se vuelve interesante para aquellos que creen que la institución de la pena, en condiciones normales de razonable justicia social (es decir, en una sociedad en la que no hubiera excluidos sociales), sí es legítima. De otro modo, la pena ya estaría condenada de antemano y por razones independientes. En las secciones siguientes mi propósito es determinar la plausibilidad de la tesis de la incapacidad en relación con algunas propuestas clásicas y contemporáneas de justificación del castigo.

\section{Castigo penal y reproche moral}

Existe un conjunto de argumentos justificatorios del castigo que poseen en común el hecho de pensar al castigo como una forma de reproche moral o como una práctica que presupone un reproche moral. Al castigar al delincuente, la sociedad está haciéndolo responsable y señalándolo como culpable frente a sus conciudadanos (o frente a las víctimas). Las teorías que más énfasis ponen en este aspecto recriminatorio del castigo son las teorías expresivistas (Feinberg 1970) y comunicativas (Duff 2001). Para estas, el castigo es, en sí mismo, una forma de expresar o de comunicar un reproche o condena social por el acto cometido.

La actividad de reprochar, expresar condena, indignación o rechazo frente a una acción que otro ha cometido parece ser una actividad para la que es necesario poseer una cierta autoridad moral. No cualquiera está en condiciones (morales) de reprochar a otro. Por ello, si cuando la sociedad le impone un castigo al delincuente lo que está haciendo es expresando o comunicando un reproche, la idea de que esta puede perder su autoridad moral para castigar a los excluidos sociales no parece descabellada. 
Veamos brevemente la cuestión de la pérdida de autoridad moral para reprochar en el plano de la moral interpersonal. En este plano, se suelen distinguir dos clases de situaciones en las que un agente moral puede perder su autoridad moral para reprochar (Cohen 2006): cuando él mismo es reprochable por un tipo de conducta similar a la que critica, y cuando él está implicado o es corresponsable de esa conducta. La primera es bautizada por Gerald Cohen como "tu quoque": una persona que miente continuamente no tiene autoridad moral para criticar o reprochar a otro porque ha mentido. Aunque existen diversas interpretaciones de esta primera situación, una habitual es identificarla con una clase de hipocresía (Tadros 2009, Wallace 2010). La segunda es la que se da cuando el que reprocha es cómplice o ha causado de algún modo la situación que lleva a alguien a cometer una falta moral. El ejemplo de Cohen es el del terrorismo. Aun cuando el terrorismo sea condenable y muchas personas puedan condenarlo, aquellos que no han dejado a una población otra salida para conseguir algún objetivo legítimo más que el terrorismo no poseen, según Cohen, autoridad moral para condenarlo (Cohen 2006, pp. 126-132). ${ }^{10}$

Existe, sin embargo, un tercer tipo de pérdida de autoridad moral para reprochar, que se da cuando el que reprocha simplemente ha incumplido deberes básicos hacia el reprochado. Un padre que ha maltratado de diversas formas a su hijo durante su crianza no puede luego reprocharle por no ocuparse de él en su vejez, aun cuando el ignorar al otro (o el no ocuparse del otro) no haya sido el tipo de maltrato que el padre ejerció sobre el hijo, y aun cuando no podamos decir que el padre sea cómplice o corresponsable de la falta de cuidado que sufre en su vejez (en el sentido de que haya contribuido causalmente al resultado). ${ }^{11}$

¿Cuál de estas formas de pérdida de autoridad moral explicaría mejor la ilegitimidad del castigo en condiciones de exclusión social? Si bien muchas veces los fenómenos de hipocresía, complicidad y maltrato se dan simultáneamente, es importante identificar cuál es el más importante o el determinante para construir un argumento a favor de la tesis de la incapacidad. Es importante que el argumento a favor de la tesis de la

${ }^{10}$ En rigor, ambas clases de argumento son casos de tu quoque, en el sentido de que son falacias de inatinencia en las que se descalifica al que reprocha acusándolo. Agradezco a Marina Velasco por llamarme la atención sobre este punto.

${ }^{11}$ En este trabajo no me ocupo de indagar las razones profundas que explican la incapacidad moral en los tres casos señalados. Esto depende, en parte, de cuál sea la función y justificación de la práctica del reproche dentro de nuestro discurso moral. Para el caso del tu quoque (hipocresía), véase Wallace (2010). Yo exploro parcialmente estas razones en el trabajo inédito "The Fragility of Our Moral Standing to Blame". 
incapacidad explique por qué el estado carecería de autoridad para reprochar a los excluidos sociales y específicamente a ellos.

La acusación de hipocresía (o tu quoque) suele ser un argumento relevante para objetar o descalificar el reproche de una persona a otra. ${ }^{12}$ Haber hecho algo similar a lo que se reprocha suele ser suficiente para que el reprochador quede inhabilitado para la crítica moral. Sin embargo, esta objeción no parece ser el elemento determinante en nuestro caso, es decir, aquello que explica por qué el estado no estaría moralmente capacitado para castigar específicamente a los excluidos sociales. En el caso de hipocresía, el reprochador pierde la autoridad moral para reprochar a cualquiera que haga lo mismo, no solamente a aquel al que le ha cometido la falta: el ladrón no puede reprochar al que roba, aun si este último, también ladrón, no ha sido robado por el primero. En el caso que nos ocupa, en cambio, la pérdida de autoridad moral para condenar penalmente ocurriría solamente respecto de los excluidos sociales, es decir, aquellos que fueron víctimas de la injusticia de la cual el estado es responsable. Un ladrón de guante blanco, por ejemplo, no podría objetar la autoridad moral del estado que lo pretende juzgar por robo aduciendo el argumento tu quoque. Obsérvese este problema con el siguiente ejemplo que utiliza Duff para defender la tesis de la incapacidad (Duff 2001, p. 186). En una institución educativa profesores y autoridades exigen a los alumnos normas de honestidad y respeto, pero ellos actúan de manera desconsiderada y deshonesta hacia los alumnos. En este caso, dice Duff, los profesores carecen de autoridad moral para acusar a una alumna deshonesta, porque "aquellos mismos que deberían responsabilizarla no han mostrado ningún respeto por los valores que ellos le acusan de estar burlando" (p. 186). A primera vista, parece que aquello que descalifica a los profesores es el argumento tu quoque. La alumna estaría diciendo: ustedes me están acusando de ser deshonesta pero ustedes son deshonestos. Si esta fuera la (única) objeción, la pérdida de autoridad moral sería más extensa: los profesores no podrían reprochar tampoco a quienes pertenecieran a otra institución educativa. El punto relevante es, en cambio, que los profesores se han comportado deshonestamente precisamente hacia la alumna que ahora desean reprochar. Un mentiroso quizá no tiene autoridad moral para reprochar a nadie por mentir, pero el punto fundamental aquí es si tiene autoridad moral para reprochar a aquel a quien el mentiroso le ha mentido sistemáticamente. ${ }^{13}$

${ }^{12}$ Desde ya, al tratarse de un argumento ad hominem, no permite inferir la falsedad del contenido del reproche.

${ }^{13}$ Es una buena pregunta por qué no consideramos que el estado pierda autoridad 
El caso de la complicidad es diferente en este aspecto. El argumento es que, cuando un agente crea las condiciones para, o hace probable, que otro cometa una falta moral, es cómplice y no está autorizado a reprochar a ese otro, aun cuando su participación no sea intencional (basta con que conozca que esa probabilidad aumenta). Victor Tadros argumenta que la sociedad, a través de sus autoridades jurídicas, ha realizado acciones de gobierno que han causado la situación de exclusión social existente, sabiendo que esta situación aumenta la tasa de delitos por parte de los excluidos. En este sentido, es corresponsable de los daños que estos puedan ocasionar. Como tales, no pueden reprochar a los autores principales imponiéndoles un castigo (Tadros 2009, pp. 404-409).

A diferencia del argumento de la hipocresía, en este caso existe una conexión más íntima entre la persona que reprocha y el reprochado que se defiende con el argumento de la complicidad. Hay una razón para pensar que solo el autor principal es aquel que tiene derecho a no ser reprochado por el cómplice. En todo caso, si el cómplice queda inhabilitado para reprochar a otros, no es por razones específicas de complicidad, sino, quizá, por razones de hipocresía (haber hecho él también algo incorrecto).

Ahora bien, aun cuando la idea de complicidad puede ser una parte importante del argumento a favor de la tesis de la incapacidad, no parece recoger un aspecto central. En la complicidad, lo que inhabilita al reproche por parte del cómplice es su corresponsabilidad por el daño o el delito cometido. No es un elemento central el hecho de que el cómplice haya, de algún modo, maltratado o violado derechos del autor principal. Sin embargo, en el caso de la exclusión social, este parece ser un elemento central: la idea de que el estado no puede pedirles cuenta a los excluidos sociales por sus delitos, fundamentalmente, porque se ha comportado mal con ellos, no porque haga más probable o participe en los delitos que ellos cometen.

Por lo tanto, el argumento central que sostiene a la tesis de la incapacidad parece ser el tercero: la víctima de un abuso o una violación de derechos no puede ser reprochada por el victimario cuando aquella, a su vez, comete alguna falta moral, salvo que la falta sea desproporcionalmente más grave. La sociedad en su conjunto,

moral frente a aquellos a quienes no maltrata, en base a un argumento tu quoque. Debe tenerse en cuenta que esta restricción (que resulta plausible en el caso del ladrón de guante blanco) implica también que la tesis de la incapacidad no se aplique en el caso de un inmigrante reciente, que ha sido excluido socialmente en su país de origen (agradezco a Juan Pablo Alonso por llamarme la atención sobre este caso problemático). 
representada a través de sus autoridades políticas (y judiciales) ha maltratado y desconocido derechos básicos de los excluidos sociales. Luego, cuando los excluidos sociales violan derechos de gravedad equivalente, la sociedad no puede pedirles cuenta por ello. Al igual que el padre maltratador, no puede reprocharle a un excluido social por no "cuidar" a la sociedad. Y esto, a pesar de ser verdadero, desde un punto de vista imparcial, que la persona acusada sea responsable y, por lo tanto, reprochable, por el delito cometido. Es solamente que esta sociedad no puede reprocharlo.

Este tercer argumento permite explicar dos aspectos importantes de la tesis de la incapacidad. En primer lugar, si la falta es desproporcionadamente más grave que el maltrato recibido, entonces ese maltrato no anula la autoridad moral para reprochar. Por ello, no cualquier delito está alcanzado por la tesis de la incapacidad. El padre defectuoso puede perder su autoridad moral para reprocharle a su hijo que no lo cuide adecuadamente en la vejez, pero sí puede reprocharle si el hijo hiciera algo mucho más grave hacia él (o hacia otros). En segundo lugar, el argumento explica por qué la tesis es más convincente en los casos de delitos de características sociales, dado que los daños involucrados son de naturaleza similar a los daños sufridos por los sectores excluidos. Es el caso de los delitos contra la propiedad. En cambio, en delitos como homicidio, violación, secuestro, torturas, etc., se trata (salvo en casos extremos de estados genocidas) de daños cualitativamente diferentes y más graves. En estos casos, la sociedad no necesariamente pierde su autoridad para reprochar. ${ }^{14}$

Podría objetarse que hay algo esencialmente disímil entre la práctica del reproche individual y la práctica del castigo estatal, que impide atribuir al estado una "pérdida" de autoridad moral para reprochar. Efectivamente, la analogía entre la moral interpersonal y la institucional es discutible (y volveré brevemente a ella en la sección VIII); sin embargo, debe tenerse en cuenta que, si las diferencias entre el

${ }^{14}$ Es sin duda un problema muy difícil el de establecer una correlación entre el delito y la violación de derechos de la que ha sido víctima el delincuente. Este es un problema recurrente en la discusión sobre pérdida de autoridad moral. No puedo abordar esta cuestión aquí. Sin embargo, podemos pensar un ejemplo de correspondencia que resulta bastante claro: personas a las que sistemáticamente se les ha vedado toda posibilidad de tener una vivienda digna usurpan y se instalan en un parque público, en el que construyen viviendas precarias. Lo que han hecho es ilegal y ellos son culpables de cometer este delito. Sin embargo, es discutible que el estado tenga la capacidad moral de castigarlos por ello. Aquí se da una similitud fuerte entre la carencia y el delito (agradezco a Gustavo Beade por el ejemplo). 
reproche individual y el castigo impiden hablar de pérdida de autoridad moral del estado, también deberían impedir hablar de reproche estatal. Sin embargo, las teorías del castigo que estoy presuponiendo hasta aquí conciben al castigo penal precisamente como un reproche que la sociedad le dirige al delincuente. Por lo tanto, al menos para estas teorías, esta objeción no es efectiva.

\section{Retribucionismo y autoridad moral para castigar}

Quizá la tesis de la incapacidad resulta menos convincente para aquellos que no hacen descansar el peso justificatorio del castigo en el reproche social. Un retribucionista clásico podría sostener que la imposición de un castigo no necesariamente implica una condena moral o la expresión de un reproche, sino la asignación de aquello que el delincuente merece, lo que es digno de él.

La cuestión que se plantea en este caso es doble: por un lado, si las teorías retribucionistas, aunque no usen el reproche como parte de su justificación, no lo implican como condición necesaria para castigar; por otro lado, si se puede perder la autoridad moral para castigar, aun cuando no esté involucrada de ningún modo una expresión de reproche. No puedo dirimir esta cuestión aquí; supondré que la impartición del castigo merecido no implica en absoluto la expresión de un reproche. ${ }^{15}$ En efecto, la actividad de reprochar no es la única que uno puede pensar que requiere un determinado estatus o autoridad moral. Otros tipos de reacción frente a una falta también pueden requerirlo. La impartición de un castigo (aunque sea merecido) como consecuencia de una falta cometida puede ser una actividad para la que se requiera cierta autoridad moral. En el ejemplo del mal padre que, en su vejez, no es cuidado debidamente por su hijo, no se trata solamente de que el padre no puede reprochar a su hijo si no lo cuida. Tampoco consideraríamos que esté habilitado para imponerle alguna clase de castigo merecido, reprimenda o carga. Por ejemplo, pensaríamos que es inadecuado de su parte avergonzarlo frente a terceros, aun cuando concedamos que el hijo merecería este tipo de sanción social si estos terceros se enteraran de su falta por otro medio.

Existen versiones contemporáneas del retribucionismo que no ponen el acento en el merecimiento moral, sino en la equidad en las cargas sociales. Jeffrey Murphy defiende la idea de que el castigo es el pago que el delincuente hace para restablecer la relación de equidad entre los

15 Si fuera cierto que el retribucionismo debe suponer un reproche social en el castigo, entonces valdría para él lo ya discutido en la sección anterior. 
miembros de una sociedad. Dado que él se ha aprovechado de la cooperación social sin asumir la carga de actuar de acuerdo con el contrato social básico (actuando como un free-rider), debe ahora pagar con una carga equivalente (Murphy 1973). En este caso, el argumento por la ilegitimidad del castigo es todavía más extremo y ha sido elaborado por el propio Murphy: si la sociedad es injusta, no puede exigir el cumplimiento de aquellos que sufren la injusticia porque el castigo no estaría restableciendo la situación de equilibrio y equidad, sino la de inequidad existente (Murphy 1973, p. 237). Los excluidos sociales no han obtenido los bienes de la cooperación, por lo cual no se les puede achacar que se estén comportando como free-riders. En algún sentido, este argumento prueba más que la tesis de la incapacidad. Implica no solamente que el estado carece de autoridad moral para castigar, sino que los delincuentes que sufren la injusticia (los excluidos sociales) no merecen el castigo, dado que no han gozado de los beneficios que ahora la sociedad les está reclamando que "paguen".

\section{La teoría consensual de la pena y la autoridad moral para castigar}

¿Qué se sigue de la teoría consensual de la pena propuesta por Nino en relación con la (in)capacidad para castigar en circunstancias de injusticia social? Como es conocido, Nino ofrece una teoría de la justificación de la pena en la que un elemento necesario para la imposición del castigo penal es el consentimiento del delincuente: al realizar el acto prohibido, el autor consiente su pérdida de su inmunidad frente a la pena (Nino 1983). Si bien la justificación o propósito general de la pena es la protección social (es decir, la prevención), el consentimiento es aquello que permite distribuir el castigo, es decir, aplicarlo a determinada persona (y no a otra):

"el hecho de que el individuo ha consentido libremente en hacerse sujeto de una pena (mediante la comisión de un acto voluntario, con conocimiento de que la pérdida de su inmunidad es un efecto necesario de él) provee una justificación prima facie para el ejercicio de la facultad correlativa de penar" (Nino 1980, p. 237).

El consentimiento es, por lo tanto, una condición necesaria para la legitimidad de la pena, y la facultad de penar de las autoridades jurídicas son el análogo a la ejecución de una deuda que voluntariamente contrajo el individuo al cometer un delito. De hecho, según Nino, 
(e)l individuo que ejecuta un acto voluntario - un delito- sabiendo que la pérdida de la inmunidad jurídica contra la pena es una consecuencia necesaria de su acto, consiente en esta consecuencia normativa, del mismo modo que un contratante consiente una consecuencia normativa que resulte del contrato (Nino 1980, p. 233).

¿Es compatible la tesis de la incapacidad con este enfoque? Es importante notar que, en la teoría de Nino, aun cuando el autor de la acción prohibida haya realizado (al llevar a cabo esa acción) un acto de consentimiento en perder su inmunidad jurídica, la aplicación de la pena no deja de ser un acto coercitivo. Como dije más arriba, es algo así como la ejecución de un contrato o una deuda. Supongamos entonces que un agente A ha violado derechos fundamentales de B. Luego, B ha contraído una deuda con A y A quiere ejecutarla. La pregunta que parece relevante es si A tiene autoridad moral para cobrarle esa deuda a B. Si la falta que A había cometido (o está cometiendo) con B es comparable a la que B ha cometido, entonces parecería que A debería darse por satisfecho: no puede exigirle el cobro a B. Análogamente: si bien el delincuente ha consentido en perder su inmunidad en caso de cometer un delito y, por lo tanto, podría ser, en principio, castigado por una autoridad jurídica, no es claro que la sociedad que (metafóricamente) está en deuda con él (porque ha violado sus derechos fundamentales), tenga la autoridad moral suficiente para ahora ejecutar coercitivamente ese acto de consentimiento. ${ }^{16}$ La idea aquí no es que las deudas se neutralicen (como podría ocurrir de acuerdo con el derecho contractual cuando dos deudores se deben mutuamente una suma equivalente de dinero). Se trata más bien del hecho de que el acreedor, por haber faltado a su deber respecto de una persona, no está en condiciones morales de exigirle a esa persona el cumplimiento de su deuda. ${ }^{17}$

Mi intención aquí no es demostrar que la tesis de la incapacidad se sigue de la teoría consensual de Nino (en contextos de injusticia social). Solo pretendo sugerir que existe un argumento para pensar que ambas son compatibles y, sumadas a una serie de otros supuestos, podrían ser simultáneamente defendidas.

${ }^{16}$ Como he señalado en la introducción, es posible que el hecho de la exclusión social pueda ser la base de un argumento diferente en contra del castigo, en el marco de la teoría de Nino. Se podría argumentar que el delincuente, al estar privado de bienes sociales básicos, no ha dado un consentimiento genuino en perder su inmunidad jurídica al realizar un acto criminal. Nino, de hecho, contempla esta posibilidad (1991/2007, pp. 143-144). Sin embargo, esta vía de argumentación no es la que me interesa indagar aquí.

17 Agradezco a Marcelo Ferrante por llamarme la atención sobre esta posible confusión. 


\section{Castigo y prevención}

El enfoque moral general consecuencialista (o utilitarista) da lugar a lo que llamaré "teoría prevencionista" del castigo. ${ }^{18}$ Según esta teoría el castigo se justifica si (y solo si) es la medida que más contribuye causalmente al beneficio social agregado. Una versión utilitarista pura, sin embargo, no es relevante para nuestra discusión, dadas las restricciones que mencioné en la sección II, referidas a la exclusión de cualquier otra forma de castigo y a la imposición de garantías procesales. Dadas estas restricciones (deontológicas) de trasfondo, la teoría prevencionista debe afirmar algo más restringido: que la institución de la cárcel se justifica porque es la medida punitiva menos lesiva de los derechos individuales (de los condenados) que, al mismo tiempo, maximiza el objetivo de conducir a una tasa de delitos óptima. En otros términos: se justifica porque, siendo la cárcel la medida coercitiva más lesiva que estamos dispuestos a aceptar, no existe otra que sea menos lesiva que obtenga un resultado igual o mejor, en términos de disminución de la tasa delictiva.

La relación entre la teoría prevencionista y la tesis de la incapacidad es radicalmente diferente a la de las teorías analizadas previamente. El prevencionista busca la protección social y no es claro que la actividad de proteger u obtener un determinado resultado socialmente agregado requiera tener determinada autoridad moral. Parece bastar con un permiso, que surge del deber consecuencialista de obtener el resultado moralmente óptimo. Una teoría consecuencialista es, de hecho, reacia a incorporar consideraciones retrospectivas, tales como el record moral de aquel que impone el castigo. Por otro lado, el castigo no es presentado en absoluto como un reproche, sino solamente como una medida de política pública orientada a obtener el beneficio social, a través de la protección de las víctimas potenciales.

Existen al menos dos clases de razones para rechazar la teoría prevencionista. La primera se refiere a la tesis empírica subyacente a la teoría, según la cual, de hecho, el castigo penal es eficiente para obtener una tasa de delito óptima (o, dicho más sencillamente, que el castigo previene el delito). Si la tesis de la prevención es falsa y existe una institución alternativa al castigo que obtiene un nivel de protección social similar, entonces el castigo no se justifica. ${ }^{19} \mathrm{En}$ segundo lugar, aun cuando

18 El representante clásico es, obviamente, Jeremy Bentham.

${ }^{19}$ No puedo detenerme a evaluar la tesis de la prevención. Solo señalo que se trata de una afirmación empírica muy difícil de confirmar. Para hacerlo, habría que comparar 
la tesis de la prevención fuera verdadera, existen razones morales de carácter deontológico que militan en contra de este tipo de justificación: el trato de personas como meros medios, la posibilidad del castigo al inocente, entre otras.

No puedo aquí valorar estos argumentos, pero es importante advertir que se trata de una discusión que excede largamente la evaluación de la tesis de la incapacidad. Si estos argumentos son plausibles (por ejemplo, si la tesis de la prevención es falsa y/o el castigo preventivo implica la violación de derechos), entonces el castigo es ilegítimo en general, no solamente aplicado a los excluidos sociales. En todo caso, estos argumentos antiprevencionistas no son específicos y no explican por qué, siendo el castigo justificable en general, no lo sería cuando es aplicado a las víctimas de la injusticia social.

\section{Los límites del argumento}

El resultado tentativo de mi exploración es que el castigo penal, especialmente en su forma actual, la cárcel, puede ser fuertemente cuestionable para muchas de las teorías justificatorias que poseen elementos no consecuencialistas (expresión o comunicación de reproche moral, merecimiento, equidad, consentimiento), cuando se aplica a poblaciones excluidas socialmente. Por otro lado, las teorías puramente prevencionistas no parecen verse afectadas por la tesis de la incapacidad. Quisiera, para concluir, hacer una serie de reflexiones que tienden a debilitar o cualificar la tesis de la incapacidad y que se aplican, en mayor o menor medida, a todas las teorías consideradas.

En primer lugar, es discutible que los argumentos de pérdida de autoridad moral se puedan aplicar de manera idéntica en casos de autoridad individual y de autoridad colectiva. El estado es un agente colectivo, constituido por miles o millones de individuos. La pérdida de autoridad moral para reprochar o, en general, para castigar no es necesariamente homogénea, dado que la responsabilidad por haber producido la exclusión social que causa esa pérdida tampoco es igual en todos los miembros de la sociedad. Por lo tanto, si la tesis de la incapacidad pretendiera justificar un programa de exención de la pena en casos de

\footnotetext{
el grado de prevención del sistema carcelario con el de sistemas alternativos. Ante la imposibilidad de realizar experimentos sociales controlados, la literatura empírica se limita a comparar aumentos (o disminuciones) marginales de disuasión de medidas concretas (aumentos de penas, por ejemplo). Para un panorama general del tema, véase Paternoster (2010).
} 
clara exclusión social, se podría objetar que este programa estaría faltando el respeto de muchos individuos que no son partícipes de la injusticia social, o que incluso luchan contra ella. ${ }^{20}$

En segundo lugar, no es claro en qué situación queda la víctima. Nuevamente, si la tesis de la incapacidad fuera utilizada para justificar la exención de la pena en ciertos casos, esto podría implicar una falta de respeto hacia las víctimas de los delitos. Esto depende de un aspecto que no he tematizado aquí: cuál es el rol de la víctima en la justificación de la pena. ${ }^{21}$

Por último, es indudable que una función del estado es la protección de sus ciudadanos (incluyendo, relevantemente, la protección de los sectores excluidos, que suelen ser especialmente vulnerables al delito). En la medida en que exista algún apoyo empírico para la tesis de la prevención, el cuestionamiento de la pena por razones de incapacidad moral encuentra un límite en este deber de protección. Queda un arduo debate acerca de si otras medidas de protección no punitivas pueden ser igualmente preventivas, sin afectar derechos individuales básicos. En cualquier caso, lo que sí podemos afirmar como resultado de mi análisis es que, salvo que seamos puramente preventivistas, la institución del castigo penal, en la medida en que la injusticia social prevalezca, estará "moralmente manchada" (Duff 2001, p. 200). ${ }^{22}$

${ }^{20}$ Esto es así, salvo que consideremos que la acción del estado que falta el respeto de derechos básicos de los excluidos sociales es una acción colectiva, es decir, de un agente colectivo. En este caso, se podría responsabilizar a este agente de manera homogénea, con independencia de la contribución de cada individuo miembro de ese colectivo. Lamentablemente no puedo profundizar este punto aquí.

21 Tadros sostiene que la reivindicación del derecho de la víctima es un deber fundamental del estado, lo cual implica que la situación del estado en condiciones de injusticia es paradójica: debe cumplir con un deber que no tiene autoridad moral para cumplir (Tadros 2009, pp. 409-413). Por otro lado, es importante destacar que nuestro orden jurídico (sobre todo a partir de la adhesión a tratados internacionales de derechos humanos) otorga a la víctima derechos importantes en el proceso penal. De cualquier modo, cuál es el grado de relevancia que la víctima debe tener en el proceso penal y cuál debe ser el rol de la víctima en la justificación de la pena son cuestiones altamente controvertidas (agradezco a Marcelo Alegre por insistir sobre este punto).

${ }^{22}$ Agradezco por sus comentarios y críticas a los editores, Marcelo Alegre y Julio Montero, y a un evaluador anónimo. También me fueron muy útiles los numerosos comentarios recibidos en el XXII Seminario Internacional de Teoría y Filosofía del Derecho, La Falda, Córdoba (septiembre, 2014). Por último, agradezco los comentarios de Gustavo Beade, Vladimir Chorny, Marcelo Ferrante, Paula Gaido, Roberto Gargarella, Nahuel Maisley y Marina Velasco. He podido contemplar algunas de las críticas recibidas. Otras (sin duda las más importantes) quedarán para futuras investigaciones. 


\section{Bibliografía}

Cohen, G. A. (2006), "Casting the First Stone: Who Can and Who Can't, Condemn the Terrorists?" en O'Hear, A. (ed.), Political Philosophy, Cambridge, Cambridge University Press, pp. 113-136.

Delgado, R. (1985), 'Rotten Social Background': Should the Criminal Law Recognize a Defense of Severe Environmental Deprivation?", Law and Inequality, 3, pp. 9-90.

Duff, A. (2001), Punishment, Communication, and Community, Oxford, Oxford University Press.

(2004), "II Might Be Guilty, but You Can't Try Me': Estoppel and Other Bars to Trial", Ohio State Journal of Criminology and Law, 1, pp. 245-259.

Feinberg, J. (1970), “The Expressive Function of Punishment", en Doing and Deserving, Princeton, Princeton University Press.

Gargarella, R. (2011), "Penal Coercion in Contexts of Social Injustice", Criminal Law and Philosophy, 5, pp. 21-38.

Green, S. (2011), "Just Desert in Unjust Societies", en Green, S. y Duff, A. (eds.), Philosophical Foundation of Criminal Law, Oxford, Oxford University Press, pp. 352-376.

Hart, H. L. A. (1968), "Prolegomenon to the Principles of Punishment", en Punishment and Responsibility: Essays in the Philosophy of Law, Oxford, Clarendon Press, pp. 1-27.

Murphy, J. (1973), "Marxism and retribution", Philosophy \& Public Affairs, 2, pp. 217-243.

Nino, C. S. (1980), Los limites de la responsabilidad penal: Una teoría liberal del delito, Buenos Aires, Astrea.

(1983), "A Consensual Theory of Punishment", Philosophy \& Public Affairs, 12(4), pp. 289-306.

(1989/2007), "Derecho penal y democracia", en Maurino, G. (comp.), Fundamentos de derecho penal, Buenos Aires, Gedisa.

(1991/2007), "La huida frente a las penas", en Maurino, G. (comp.), Fundamentos de derecho penal, Buenos Aires, Gedisa.

(1992/2007), "Respuesta a Zaffaroni", en Maurino, G. (comp.), Fundamentos de derecho penal, Buenos Aires, Gedisa.

Paternoster, R. (2010), "How Much do We Really Know about Criminal Deterrence?", The Journal of Criminal Law and Criminology, 100, pp. $765-824$.

Rawls, J. (1971), A Theory of Justice, Oxford, Oxford University Press. Rivera López, E. (2013), "Nonideal Ethics", en Hugh LaFollette (comp.), International Encyclopedia of Ethics, Willey-Blackwell. 
Tadros, V. (2009), "Poverty and Criminal Responsibility", Journal of Value Inquiry, 43, pp. 391-413.

Wallace, R. J. (2010), "Hypocrisy, Moral Address, and the Moral Standing of Persons", Philosophy \& Public Affairs, 38(4), pp. 307-341.

Recibido el 21 de septiembre de 2014; aceptado el 4 de diciembre de 2014. 